\title{
Multi-temporal influence of vegetation on soil respiration in a drought- affected forest
}

\author{
Josep Barba ${ }^{(1-2)}$, \\ Francisco Lloret ${ }^{(1-2)}$, \\ Rafael Poyatos ${ }^{(1-3)}$, \\ Roberto Molowny-Horas ${ }^{(1)}$, \\ Jorge Curiel Yuste ${ }^{(4-5)}$
}

\begin{abstract}
Aboveground plant activity influences fine roots and rhizosphere activity, which is reflected on soil respiration (SR). However, it is still unclear and poorly understood the nature of plant activity control over SR, especially under drought conditions. We studied the plant activity-SR relationship at different timescales in a water-limited mixed Mediterranean forest where Scots pines (Pinus sylvestris L.) are undergoing drought-induced die-off and are being replaced by the more drought-resistant Holm oak (Quercus ilex L.). Half-hourly sap flow (SF), as a proxy of photosynthesis, coupled with measures of SR using solid-state $\mathrm{CO}_{2}$ sensors, were monitored during nine months in four different trees, representative of the diversity and health condition of the forest. SF was strongly associated with SR at both daily and seasonal timescales. At daily timescales, almost no lags were found between SF and SR, indicating a fast control of photosynthesis on SR. However, the association between SF and SR weakened during the summer drought. These temporal patterns were not constant across the trees representing the die-off and replacement processes. SR beneath living pines was highly controlled by SF at daily scale, whereas Holm oak seemed to be more controlled by SF at seasonal scale. The relationship between SF and SR measured beneath dead pine and Holm oak at the daily and seasonal scales was consistent with the colonization of soil gaps by holm oak roots following Scots pine death and suggests that surviving Scots pines are unable to expand their root system in these gaps. Our results collectively show how drought modulates the link between canopy photosynthesis and soil respiration, and increase our understanding on how belowground processes may be affected by the successional dynamics following drought-induced forest mortality.
\end{abstract}

Keywords: Soil Respiration, Sap Flow, Scots Pine (Pinus sylvestris), Holm Oak (Quercus ilex), Drought, Die-off, Functional Colonization, Mediterranean Ecosystem

the addition of plant litter and exudates into the soil. Vegetation can also indirectly control soil respiration by modifying soil abiotic conditions, e.g., the solar radiation reaching the soil, and thus, soil moisture and soil temperature (Binkley \& Giardina 1998, Yuan et al. 2012). Despite the existence of a large consensus on the crucial role that plant activity plays on SR, there are several issues that are still poorly understood, hence hindering our comprehension of the mechanisms underlying the link between plant carbon assimilation and SR, especially in Mediterranean ecosystems where drought may also modulate this relationship.

Firstly, the influence of plant activity on SR and its different components varies depending on the temporal scale at which they are considered (Tang \& Baldocchi 2005, Vargas et al. 2011). For instance, seasonal changes in plant leaf area are strongly coupled with seasonal changes in SR (Curiel Yuste et al. 2004) because, at this time berg et al. 2001), but also via the stimulation of heterotrophic respiration through

(1) CREAF, Cerdanyola del Vallès, 08193 Barcelona, Catalonia (Spain); (2) Univ. Autònoma Barcelona (UAB), Cerdanyola del Vallès, 08193 Barcelona, Catalonia (Spain); (3) Laboratory of Plant Ecology, Faculty of Bioscience Engineering, Ghent University, Coupure Links 653, Ghent 9000 (Belgium); (4) BC3 - Basque Centre for Climate Change, Scientific Campus of the University of the Basque Country, 48940 Leioa (Spain); (5) IKERBASQUE - Basque Foundation for Science, Maria Diaz de Haro 3, 6 solairua, 48013 Bilbao, Bizkaia (Spain)

@ Josep Barba (jbarba@udel.edu)

Received: Apr 01, 2017 - Accepted: Jan 09, 2018

Citation: Barba J, Lloret F, Poyatos R, Molowny-Horas R, Curiel Yuste J (2018). Multi-temporal influence of vegetation on soil respiration in a drought-affected forest. iForest 11: 189-198. - doi: 10.3832/ifor2448-011 [online 2018-03-01] 
scale, soil metabolic activity is strongly dependent on the capacity of plants to supply carbohydrates to belowground compartments. However, the possible controls of plant activity over day-to-day variations in SR seem to be very site-dependent and subject to phloem transport lags (Kuzyakov \& Gavrichkova 2010, Mencuccini \& Holtta 2010). In fact, when working with temporal series it is difficult to infer causality between variables that show lagged responses. Several studies have reported time lags between photosynthesis and SR from few hours to several days (Högberg et al. 2001, Tang \& Baldocchi 2005, Vargas et al. 2011). Canopy activity and soil respiration may be linked either by direct $C$ transport by the phloem or by pressure-signal waves, which could partially explain differences in these time lags (Kuzyakov \& Gavrichkova 2010, Mencuccini \& Holtta 2010). However, it is unclear how methodological differences (interruption of assimilates flow from leaves to roots, $C$ isotopic tracing from leaves to roots, or time series analysis of $\mathrm{CO}_{2}$ fluxes from soil and related to photosynthesis proxies) could be influencing the observed time lags between both processes (Kuzyakov \& Gavrichkova 2010, Mencuccini \& Holtta 2010).

Secondly, the interpretation of the relationship between SR and plant activity (Janssens et al. 2001) may be hindered by the inherent correlation between the environmental drivers, since solar radiation determines, directly or indirectly, the daily cycle of many environmental variables such as air and soil temperature or photosynthetic solar radiation. Determining which is the effect of temperature on both SR and photosynthesis is particularly important to disentangle the direct influence of photosynthesis on SR (Vargas et al. 2011).

Finally, it is difficult to obtain simultaneous, high-resolution data of SR and photosynthesis at the tree level under field conditions, due to methodological and technical constraints. Continuous measurements of photosynthesis at the tree level have recently performed at few experimental sites (Barton et al. 2010), but the high equipment costs and logistical limitations (e.g., installing soil respiration system inside the whole-tree chamber equipment) hinders the more broadly use of these techniques to understand the mechanisms linking photosynthesis and SR. Time series analysis, one of the most used approaches for studying this above-belowground relationship at diel to seasonal scales (Kuzyakov \& Gavrichkova 2010), has usually been performed to analyse variations in SR in relation to ecosystem-scale proxies for photosynthesis (gross primary production [GPP] obtained from eddy covariance measurements) or to variations in the main photosynthesis drivers (photosynthetically active radiation [PAR] or vapor pressure deficit [VPD] - Ekblad et al. 2005, Tang et al. 2005, Gaumont-Guay et al. 2008). However, ecosystem-level measurements do not allow to identify the link between SR and photosynthesis in co-occurring trees belonging to different species and/or exposed to different levels of disturbance caused by pests or climate variability (e.g., drought-induced die-off). In this regard, tree individual measures of SF may be a good proxy of photosynthesis, despite its limitations due to variations in water-use efficiency (WUE), especially in water-limited ecosystems (Reichstein et al. 2002). Nevertheless, SF can explain a much larger fraction of seasonal assimilation variability than WUE (Hu et al. 2010), even in water-limited forests. SF also incorporates the tree-specific physiological behaviour as opposed to approaches using PAR or VPD as proxies of photosynthesis (Ekblad et al. 2005, Vargas et al. 2011) or GPP from Eddy Covariance (EC) systems. In fact, EC systems do not measure GPP but estimate it by means of net ecosystem exchange measurements, which is later used via flux partitioning to calculate GPP. This introduce another source of errors to compare GPP and SR (Barba et al. 2017). The tree-specific physiological behaviour is essential to study the fine-scale effects of spatially diffuse disturbances on C fluxes, because the resulting stands often present a mixture of different species and of trees with different degrees of damage.

In the Mediterranean basin, the increment of frequency and intensity of drought events during the last decades, together with the progressive abandonment of forest management (Vayreda et al. 2011), are likely promoting an increase in drought-induced forest die-off episodes (Carnicer et al. 2011). These forest decline processes result in partial defoliation of water-stressed trees, tree mortality of vulnerable species and the occupation of forest gaps by more drought-resistant species (Martínez-Vilalta \& Lloret 2016). Potential vegetation shifts following forest die-off of dominant canopies (Lloret et al. 2012) and an increment of dead biomass (both below and aboveground) could have important consequences on photosynthesis activity and SR, that could in turn modify the forest capability to act as net carbon sink or source (Anderegg et al. 2013). Moreover, drought weakens the link between aboveground activity and belowground processes (Ruehr et al. 2009), but the relationship between canopy photosynthesis and soil respiration in the context of drought-induced decline is poorly known.

Here, we study the multi-temporal link between continuously-measured $\mathrm{SR}$ and xylem sap flow (SF) - as a proxy for photosynthesis - in a Mediterranean forest undergoing Scots pine (Pinus sylvestris L.) dieoff (Martínez-Vilalta \& Piñol 2002) and its progressive replacement by the more drought-resistant Holm oak (Quercus ilex L. - Vilà-Cabrera et al. 2013). These droughtinduced die-off processes have been reported in several Scots pine populations across the dry edge of its geographical distribution (Bigler et al. 2006, Galiano et al.
2010) and often results in mixed forests where non-defoliated pines (NDP), defoliated pines (DFP), dead pines (DP) and Holm oaks (HO) co-occur. These four stages of the die-back process and species replacement have been associated with: (i) differences in soil respiration at spatial and temporal scales (Barba et al. 2013, 2016a); (ii) shifts in the relative contribution of autotrophic and heterotrophic components (Pereira-Blanco 2014, Barba et al. 2016a); (iii) differences in soil microbial composition (Curiel Yuste et al. 2012); and (iv) organic matter decomposition (Barba et al. 2016b). We chose representative trees from the different stages of Scots pine dieoff and replacement by Holm oak (NDP, DFP, DP and HO) for continuous measurements of SR and SF. Wavelet coherence analyses and linear models were used to (i) determine the direct relationship of SF on SR from diel to seasonal scales, regardless of temperature variations, and (ii) to quantify the time lags between SR and SF. We also (iii) explored possible changes in SF controls over SR along the Scots pine dieoff and Holm oak replacement gradient.

\section{Materials and methods}

\section{Study site}

The study was conducted in a mixed Mediterranean forest $\left(41^{\circ} 19^{\prime} 58.05^{\prime \prime} \mathrm{N}, 01^{\circ} 00^{\prime}\right.$ $52.26^{\prime \prime} \mathrm{E}$ ) in the northwest slope of the Titllar Valley (Prades Mountains, NE Iberian Peninsula). The climate is Mediterranean, with mean annual temperature of $11.2{ }^{\circ} \mathrm{C}$ and precipitation of $664 \mathrm{~mm}$ (Ninyerola et al. 2007). The experimental area was located at an elevation of 1010-1030 m a.s.l. within a relatively high steep slope $\left(33^{\circ}\right)$. Soils are Dystic Cambisols with clay loam texture and a high gravel content of $46 \%$. Fractured Paleozoic metamorphic schists outcrops on to a large part of the study area. For more information related to the study area, see Barba et al. (2013).

This mixed forest, which has not been managed for the last $30 \mathrm{yr}$ (Heres et al. 2012), is dominated by Scots pine (Pinus sylvestris L.) in the overstorey and Holm oak (Quercus ilex L.) in the understorey. Severe drought events since 1990 s have produced Scots pine population die-off, with a mean crown defoliation of $52 \%$ and standing mortality of $12 \%$ (Vilà-Cabrera et al. 2013). This situation, coupled with low regeneration of pines, high establishment of seedlings and saplings of oaks and the much lower impact of drought on mature Holm oaks, is fostering the replacement of pines by oaks as the overstorey dominant species (Vilà-Cabrera et al. 2013).

For SR measurements, we selected four trees (one non-defoliated pine - NDP, one defoliated pine - DFP, one dead pine - DP, and one Holm oak - HO) within a maximum distance between them of $25 \mathrm{~m}$. The defoliated pine had less than $50 \%$ of green leaves, visually estimated as the percentage of green needles relative to a healthy 
canopy of a similar sized tree from the same population (Galiano et al. 2010). Sap flow (SF) was measured in NDP, DFP and $\mathrm{HO}$ trees, coupled to SR measurements.

Soil environmental and meteorological measurements

A data acquisition system (CR1000 datalogger and AM16/32 multiplexers, Campbell Scientific Inc., Logan, UT, USA) was used to store 30 min means of soil temperature $\left(T_{\mathrm{s}}\right)$, volumetric soil water content $(\theta)$, sap flow (SF) and meteorological variables sampled every $30 \mathrm{~s}$. Means of $\mathrm{CO}_{2}$ concentrations measured twice per hour during 5 min were stored with the same acquisition system. A $16-\mathrm{m}$ tower was installed less than $100 \mathrm{~m}$ from the farthest tree with sensors for measuring air temperature and air relative humidity (CS215, Campbell Scientific Inc.), precipitation (52203, R.M. Young Company, Traverse City, MI, USA), total solar radiation (SP1110, Skye Instruments Ltd, Llandrindod Wells, Powys, UK) and wind speed (05103-5, R.M. Young Company). $T_{s}$ at $5 \mathrm{~cm}$ depth was measured within 2-meters of each tree with thermocouple sensors. Average volumetric soil water content $(\theta)$ in the upper $30 \mathrm{~cm}$ of soil was monitored using a frequency domain reflectometer (CS616, Campbell Scientific Inc.) installed among the studied trees. Since automatic measurements were likely affected by the great stoniness, monitored $\theta$ were regressed against volumetric soil water content measured in soil samples (for more details, see Poyatos et al. 2013).

\section{Soil respiration}

Soil $\mathrm{CO}_{2}$ concentrations ( $\mathrm{ppm}$ ) were measured within 2-meters of each tree using Vaisala CARBOCAP $\mathrm{CO}_{2}$ sensors (models GMT220, Vaisala, Helsinki, Finland) from April 2010 to December 2010. Despite tree root systems are laterally expansive and its belowground delineation is challenging, we could assume that this set-up was adequate for our purpose. Indeed, previous studies showed that a single tree determined several autotrophic and heterotrophic components of SR in a 3-meter belt around the stump (Barba et al. 2013, 2016a), soil organic matter decomposition (Barba et al. 2016b) and soil microbial community (Curiel Yuste et al. 2012) at different temporal scales. At each location, two $\mathrm{CO}_{2}$ sensors were installed at different soil depths ( 1 and $5 \mathrm{~cm}$ ). The operation of the $\mathrm{CO}_{2}$ sensors was relay-controlled to minimise the electric power demand and prevent any undesired effects on SR of sensor self-heating (Riveros-Iregui et al. 2008). At half-hourly intervals, soil $\mathrm{CO}_{2}$ concentrations were measured once every $30 \mathrm{~s}$ during a 5-min period, and subsequently averaged over that period. The $\mathrm{CO}_{2}$ concentrations readings were continuously corrected for variations in $T_{\mathrm{s}}$ and air pressure (Tang et al. 2003). Soil $\mathrm{CO}_{2}$ efflux was estimated for each tree from soil $\mathrm{CO}_{2}$ concentrations measured at 1 and $5 \mathrm{~cm}$ depths using a flux gradient method based on Fick's law of diffusion (eqn. 1):

$$
F=-D_{s} \frac{\partial C}{\partial z}
$$

where $F$ is the SR $\left(\mu \mathrm{mol} \mathrm{m} \mathrm{m}^{-2} \mathrm{~s}^{-1}\right), D_{\mathrm{s}}$ is the gaseous diffusion coefficient of $\mathrm{CO}_{2}$ in the soil and $\partial C / \partial z$ the vertical soil $\mathrm{CO}_{2}$ gradient. $D_{\mathrm{s}}$ can be estimated as (eqn. 2 ):

$$
D_{s}=\xi D_{a}
$$

where $\xi$ is the gas tortuosity factor and $D_{a}$ is the $\mathrm{CO}_{2}$ molecular diffusivity of $\mathrm{CO}_{2}$ in the free air.

The effect of temperature and pressure on $D_{a}$ is given by (eqn. 3):

$$
D_{a}=D_{a 0}\left(\frac{T}{T_{0}}\right)^{1.75}\left(\frac{P_{0}}{P}\right)
$$

where $D_{a 0}$ is the reference value of $D_{a}$ at $T_{0}$ $(293.15 \mathrm{~K})$ and at $P_{0}\left(1.013 \times 10^{5} \mathrm{~Pa}\right)$, and is given as $1.47 \times 10^{-5} \mathrm{~m}^{2} \mathrm{~s}^{-1}$ (Jones 1992).

To calculate the tortuosity factor, the most commonly used Millington-Quirk's model (Millington \& Quirk 1961) was applied (eqn. 4):

$$
\xi=\frac{\alpha^{10 / 3}}{\phi^{2}}
$$

where $\alpha$ is the volumetric air content (airfilled porosity), and $\phi$ represents the porosity, which can be calculated as the sum of $\alpha$ and the volumetric water content $\theta$ (eqn. 5):

$$
\phi=\alpha+\theta=1-\frac{\rho_{b}}{\rho_{m}}
$$

where $\rho_{\mathrm{b}}$ is the bulk density and $\rho_{\mathrm{m}}$ the particle density for the mineral soil calculated for soil samples close to each pair of $\mathrm{CO}_{2}$ sensors.

The main goal of this study was to explore the temporal pattern of SR but not its absolute values and therefore no chamber-based SR measurements were done to calibrate the fluxes obtained from the soil $\mathrm{CO}_{2}$ profiles. In general, SR measurements obtained from soil $\mathrm{CO}_{2}$ concentration profiles are linearly correlated with reference measurements (see Maier \& Schack-Kirchner 2014 for references). Hence, the analyses of the temporal patterns of SR in this paper are robust to the uncertainty in the absolute values of SR.

\section{Sap flow measurements}

Sap flow per unit sapwood area (SF, kg $\mathrm{m}^{-2} \mathrm{~s}^{-1}$ ) was recorded as a proxy for the time course of photosynthetic activity in the same living trees (one non-defoliated pine, one defoliated pine and one Holm oak), concurrent with SR measurements. Sap flow density in the outer xylem was measured with constant heat dissipation sensors (Granier 1985) manufactured in our laboratory. Probe length was $2 \mathrm{~cm}$ in Scots pine and $1 \mathrm{~cm}$ in Holm oak. In April 2010, probe pairs were inserted into the xylem at breast height with a vertical separation of $12 \mathrm{~cm}$ and covered with reflective bubble wrap to minimise natural temperature gradients. Outer-xylem sap flow density values were corrected for temperature gradients within the stem and up-scaled to the treelevel using tree sapwood area and speciesspecific corrections to account for radial variations of sap flow density within the xylem (see Poyatos et al. 2013 for detailed information).

\section{Removing the effect of temperature on} SF and SR

The direct inference of causality from SF to SR could overestimate the contribution of photosynthetic activity on SR because the diurnal solar radiation cycle drives changes in temperature, which in turn, influences many variables including SR, SF or air diffusivity, possibly leading to spurious correlations (Vargas et al. 2011). Thus, in our analysis of the relationship between SF and SR we removed the effect of changes in temperature both on SR and SF. The direct effect of temperature on SR was removed for each tree using the exponential fit equation (eqn. 6):

$$
S R_{c}=S R-B_{1} \exp ^{\left(B_{2} \cdot T_{s}\right)}
$$

where $S R_{c}$ is the soil respiration corrected by temperature, $S R$ is the soil respiration estimated using the Fick's law of diffusion from $\mathrm{CO}_{2}$ measurements (eqn. 1), while $B_{1}$ and $B_{2}$ are parameters evaluated for each single day based on half-hourly $T_{\mathrm{s}}$ measurements. Additionally, temperature also influences SR indirectly, modifying the gaseous diffusion coefficient $\left(D_{5}\right)$ of $\mathrm{CO}_{2}$ in the soil. Thus we removed for each tree the effect of changes in $D_{s}$ on $S R_{r}$ (eqn. 7):

$$
S R_{r}=S R_{c}-\left(B_{3}+B_{4} \cdot D_{s}\right)
$$

where $S R_{r}$ is the soil respiration corrected by $T_{\mathrm{s}}$ and $\mathrm{CO}_{2}$ diffusivity, $\mathrm{SR}_{\mathrm{c}}$ is the soil respiration corrected by $T_{s}$ (residuals from eqn. 6) and $B_{3}$ and $B_{4}$ are parameters calculated for each day based on half hour $D_{s}$ estimations obtained with the eqn. 2 .

SF was also temperature-corrected by fitting a simple linear regression to each tree (eqn. 8):

$$
S F_{r}=S F-\left(B_{5}+B_{6} T_{a}\right)
$$

where $S F_{r}$ is the corrected sap flow, $S F$ is the measured sap flow and $B_{5}$ and $B_{6}$ are parameters evaluated for each single day based on half hour air temperature $\left(T_{a}\right)$ measurements.

\section{Wavelet coherence analyses}

Wavelet coherence analyses were applied to assess the relationship between $S R_{r}$ and $\mathrm{SF}_{\mathrm{r}}$ for each tree at multi-temporal scales. Since the time series data presented two main gaps, wavelet coherence analysis for each pair of variables were split in three different parts. Wavelet coherence analysis 


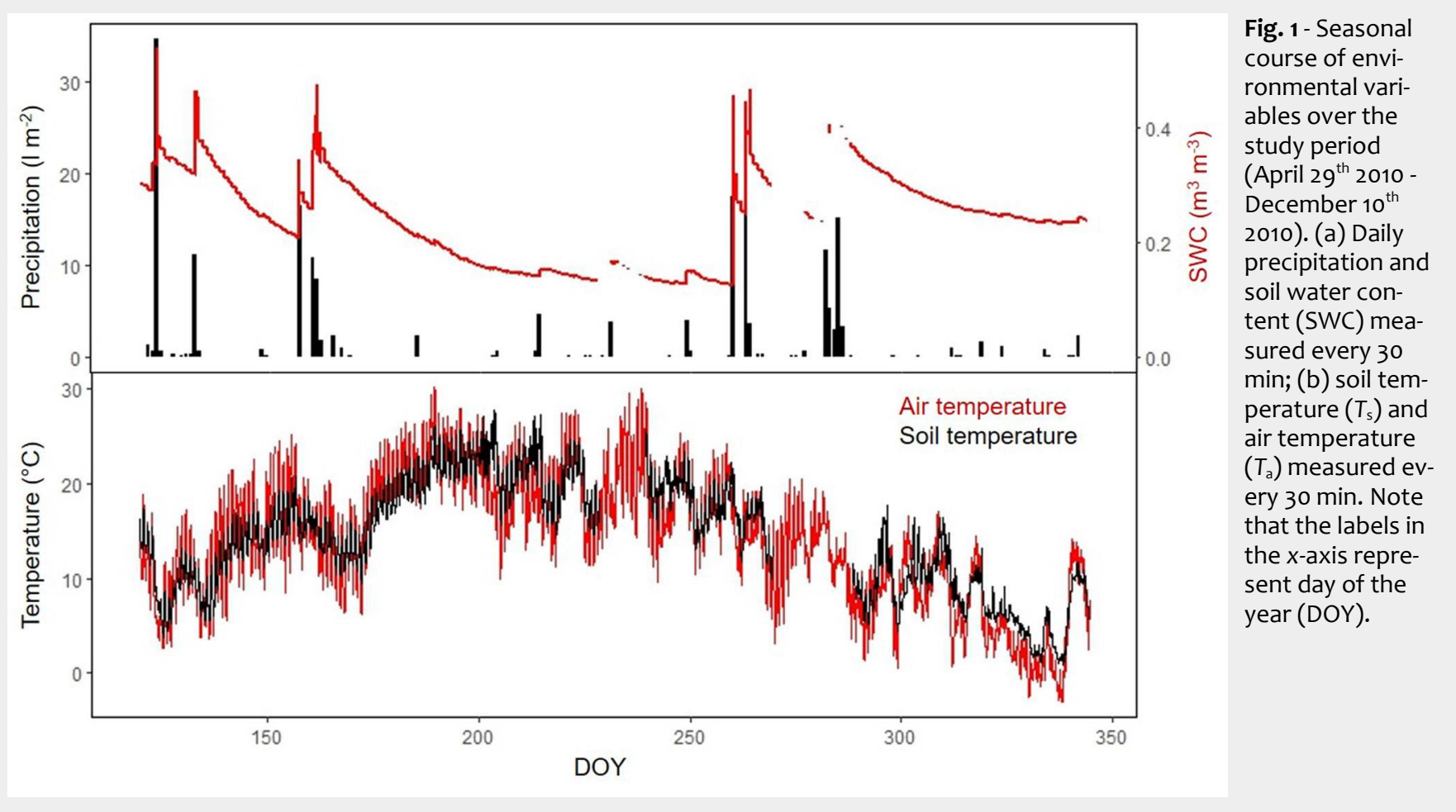

is best suited for studying transient signals (oscillatory or non-oscillatory), or signals whose amplitude varies in time. This method is widely used in the field of signal processing, in cases where the signal is localized both in time and frequency (Torrence \& Compo 1998). Since we were interested in the relationship between transient signals that may be present in two different time series, we calculated the cross-wavelet transform and wavelet coherence pairwise to the dataset (for an introduction to this topic, see Grinsted et al. 2004). As the set of wavelet basis functions we chose the Morlet's function, implemented in the wavelet software available at http://paos. colorado.edu/research/wavelet/. The wavelet coherence can be thought as a "localized correlation coefficient in time frequency space" (Grinsted et al. 2004). The calculations have been performed in MATLAB $^{\oplus}$ R2009b (MathWorks, Natick, MA, USA).

The wavelet analysis was calculated for each living tree (NDP, DFP and $\mathrm{HO}$ ) between its temperature-detrended time series soil respiration $\left(S R_{r}\right)$ and its temperature-detrended time series sap flow $\left(S_{\mathrm{r}}\right)$. Additionally, wavelet analysis was calculated between DP $S R_{r}$ and NDP $S F_{r}$, and DP $S R_{r}$ and $H O S F_{r}$ to test which tree type (NDP or $\mathrm{HO}$ ) had the largest influence on $S R_{r}$ beneath dead pines. SR and SF data used for wavelet analysis were at half-hourly intervals. Additional wavelet analyses were carried out between SR-Temp, SR-SF, SF-Temp and SR-SWC to test the multi-temporal correlations between SR and the environmental drivers (see Supplementary Material).

To test for differences in the diel coherence between SF and SR associated to the drought-induced die-off gradient, we first extracted wavelet coherence curves (wavelet correlation values) for a 1-day period for NDP, DFP and HO. These curves were derived from wavelet coherence plots. Consecutive time points along the $x$ axis (time) in those figures were clearly not independent due to the finite width of the Morlet wavelet, which in turn depends inversely on the period ( $y$-axis). Consequently, to ensure independence we chose points along the $x$-axis separated by twice the width of the corresponding cone of influence for a 1-day period (Torrence \& Compo 1998). We then compared the resulting NDP and DFP curves with the HO ones for each of the three time series measured. A Mann-Whitney $U$ test was applied to test for significant differences between those curves.

\section{Analyses at the seasonal scale}

Daily aggregates of SR, $T_{\mathrm{s}}$ and SWC data were directly calculated by averaging the half-hourly data over $24 \mathrm{~h}$. SF was averaged only over the midday hours (from 11:00 to $13: 00$ ), since this variable is more dependent on environmental conditions than the whole day average. To assess the influence of SF on SR at the seasonal scale, daily values of SR for each tree were fitted with a linear model using midday-averaged SF and daily averages of $T_{\mathrm{s}}$ and SWC as predictors. Daily SR and SF were not temperature-detrended in these seasonal analyses, so $T_{s}$ and SWC were included in models as predictor variables, in order not to overestimate the SF contribution on SR. For each tree, all models combining SF, $T_{s}$, SWC and their first-order interactions were evaluated to achieve the minimum adequate model according to the corrected Akaike information criterion (AICC), using the "MuMIn" package in R ( $R$ Foundation for Statistical Computing, Vienna, Austria). SF from both NDP and $\mathrm{HO}$ were included as predictors in the DP saturated model to test which of the two variables had the largest influence on seasonal variability of SR in DP. SR, SF and SWC were log-transformed to introduce a SR-exponential response to $T_{s}$ in daily-averaged data analysis. Analyses of linear models at daily level were carried out using $R$ ver. 3.0.3.

\section{Results}

\section{Seasonal course of environmental} variables, soil respiration and sap flow Over the study period, accumulated precipitation was $197.5 \mathrm{~mm}$. Precipitation peaked in spring and autumn, determining the observed SWC seasonal pattern (mean SWC was $23.8 \%$ - Fig. 1a). $T_{\mathrm{s}}$ ranged from 0 to $29.5^{\circ} \mathrm{C}$ with a mean of $14.3^{\circ} \mathrm{C}$ (Fig. 1b). SR increased from spring to summer, peaking in mid-July, when $T_{\mathrm{s}}$ achieved maximum values (more than $20^{\circ} \mathrm{C}$ ) and SWC was near its minimum (Fig. 2, Fig. 1b). From mid-summer to the beginning of autumn rains, variations in SR were strongly coupled with fluctuations in SWC. The low temperature at the end of September concurred with low SR rates until the end of the experiment (December 2010). All trees showed similar seasonal pattern, although it was clearer in DFP, DP and HO than in NDP, where the seasonal variability of SR was less accentuated (Fig. 2). SF showed similar temporal patterns for NDP and DFP, maintaining high values during spring and decreasing drastically along the summer, fol- 


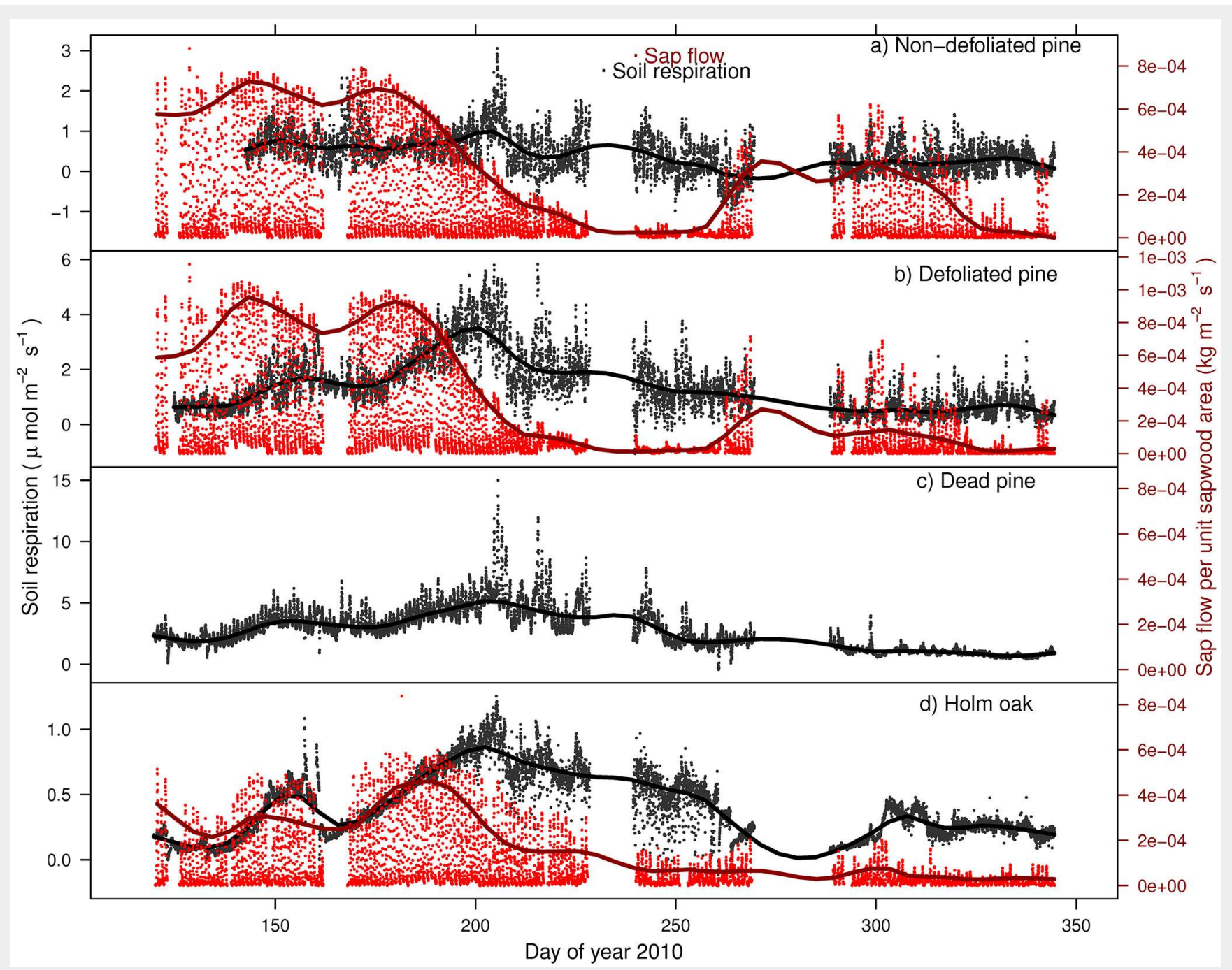

Fig. 2 - Seasonal course of soil respiration (SR) and sap flow per unit sapwood area (SF) associated to: (a) non-defoliated pine (NDP); (b): defoliated pine (DFP); (c) dead pine (DP); Holm oak (OH). SF for the dead pine is that measured under HO (see Results). Points are half-hourly measurements taken from DOY 142 to 344 (April $29^{\text {th }} 2010$ - December $10^{\text {th }} 2010$ ) and lines depict smoothed seasonal patterns for SR and smoothed patterns of midday values for SF. Please note that the scales on $y$-axes vary across panels because we are interested in the temporal relationship between SR and SF, not in the differences in absolute values of SR or SF across tree types.

lowing the reduction in SWC (Fig. 2). Autumn rains stimulated pines SF, which decreased again at the end of autumn. HO showed a less steep decrease in SF during summer, and there was a very small response of SF to autumn rains.

\section{Daily patterns of $S F_{r}$ and $S R_{r}$ relation- ship with high-resolution data}

The wavelet analysis of $\mathrm{SR}_{\mathrm{r}}$ and $\mathrm{SF}_{\mathrm{r}}$ (temperature-detrended soil respiration and sap flow time series) during the study period showed the strongest synchrony between the two signals with a period of one day in NDP and DFP (Fig. 3). However, summer drought weakened the daily relationship between $S R_{r}$ and $S F_{r}$ in NDP and DFP (Fig. 3). For these variables, NDP and DFP showed similar wavelet patterns over the study period at daily scale. These trees showed high daily correlation during spring and part of the summer (Fig. 3a.1 and Fig. 3b.1) when SF fluxes were high, but there was a lack of correlation at the end of summer (Fig. 3 a.2 and Fig. 3b.2) when $\mathrm{SF}_{\mathrm{r}}$ fluxes drastically decreased. In living pines, autumn rains stimulated $S F_{r}$, and thus, the correlation between $S R_{r}$ and $S F_{r}$ increased again (Fig. 3a.3 and Fig. 3b.3), but it was not as high as in spring. The $S R_{r}$ and $S F_{r}$ datasets for NDP and DFP were mainly in phase for the 1-day periodic signal component (arrows pointing mostly to the right in Fig. 3), which means that these variables approximately varied simultaneously (i.e., no major lags between variables). Similar results were observed when diurnal cycles of SR and SF were compared within seasons (Fig. 4). The wavelet analysis between $S R_{r}$ and $S F_{r}$ for HO showed a weaker correlation over the study interval at a daily scale (Fig. 3, panels e) except for some short time intervals during spring and midsummer; during these intervals the two sig- nals were in phase. HO diurnal cycle showed a drop in SR at midday whereas SF achieved its maximum during spring and summer (Fig. 4). Similar results were found when wavelet analyses were performed between DP SRr and SFr (either from NDP or $\mathrm{HO}-$ Fig. $3 \mathrm{C}$ and Fig. 3d, respectively). Results depicted in Tab. 1 also showed that wavelet coherence at diel scales was significantly larger in NDP and DFP trees than in the Holm oak tree, but only for the first time series (Spring-Summer).

\section{SF seasonal influence on SR with daily} data

The linear model of daily SR revealed a strong association between SR and SF, modulated by the seasonal patterns of temperature and soil moisture. For NDP, the SR linear model included the interactions between $T_{\mathrm{s}}$ and SF and between SWC and SF (Tab. 2 - NDP) but it only explained 

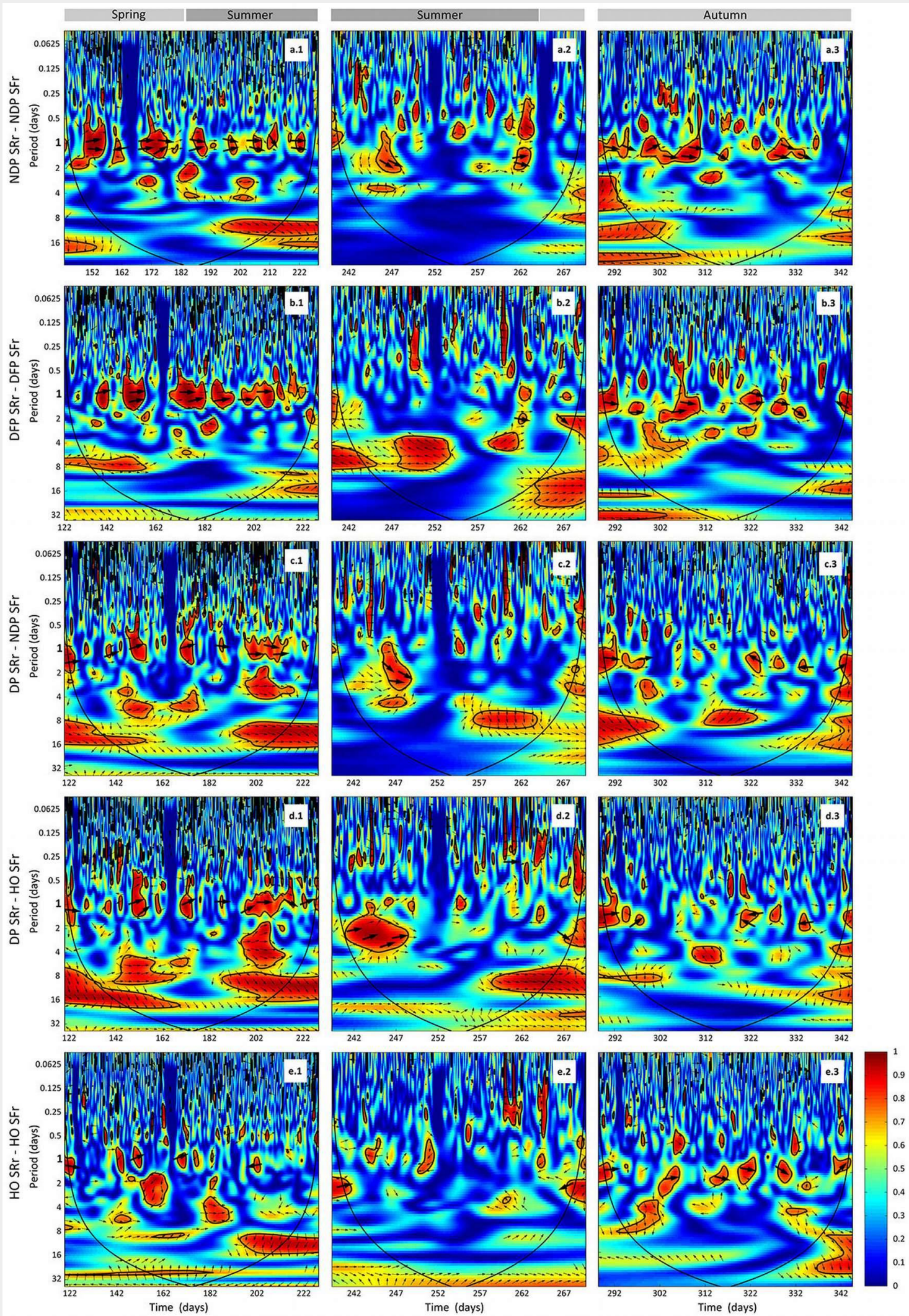

Fig. 3 - Cross wavelet analyses output and phase differences between corrected soil respiration ( $\left.S R_{r}\right)$ and corrected sap flow (SF $)$ from DOY 142 to 228 (April $29^{\text {th }} 2010$ - December $10^{\text {th }} 2010$ ) measured every 30 min. Two gaps in the time series (from DOY 228 to 239 and 269 to 288), due to power failures, required splitting each wavelet coherence analysis in three series (1, 2 and 3, left to right). (a.1, a.2, a.3): $S R_{r}$ and $S F_{r}$ from non-defoliated pine (NDF) analysis; (b.1, b.2, b.3); $S R_{r}$ and $S F_{r}$ from defoliated pine (DFP) analysis; (c.1, c.2, c.3): $S R_{r}$ from dead pine (DP) and $S F_{r}$ from non-defoliated pine (NDP) analysis; (d.1, d.2, d.3): $S R_{r}$ from dead pine (DP) and $S F_{r}$ from Holm oak (HO) analysis; (e.1, e.2, e.3): $S R_{r}$ and $S F_{r}$ from Holm oak (HO) analysis. Arrows pointing to the right indicate that the two signals are in phase; arrows pointing downward indicate that $S R_{r}$ delays the other variable by $90^{\circ}$; arroes pointing upward indicate that $S R_{r}$ leads the other variable by $90^{\circ}$. The colour codes for power values are from dark blue (low values) to dark red (high values). Black lines contouring red areas represent the $5 \%$ significance level as calculated by 1000 Monte Carlo simulations ( $G$ rinsted et al. 2004). The other black lines indicate the cone influence that delimits the region not affected by edge effects. 
Fig. 4 - Diel patterns of sap flow per unit sapwood area (SF) and soil respiration (SR) for dif-

ferent seasons. Solid lines depict mean values for each hour of the day and dashed lines represent standard errors. Please note that the scales on $y$-axes vary across panels because we are interested in the temporal relationship between SR and SF, not in the differences in absolute values of SR or SF across tree types.
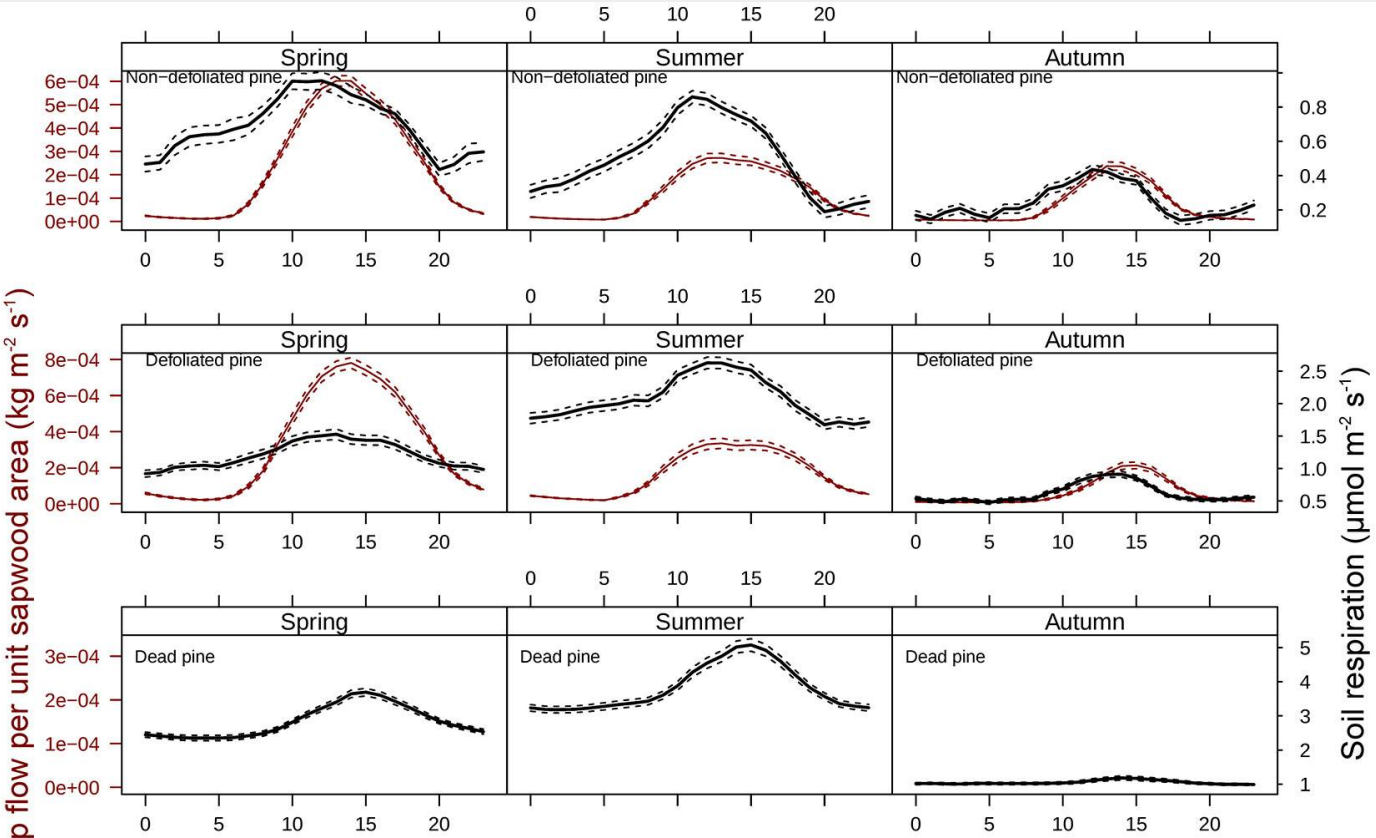

ळ

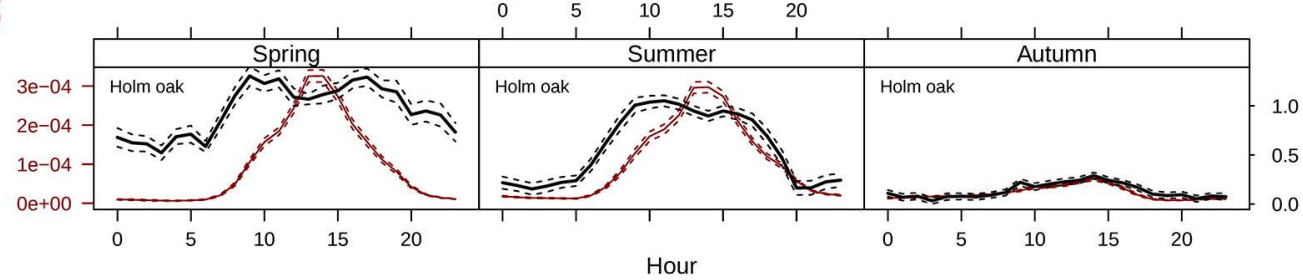

Tab. 1 - Results of the Mann-Whitney U test between 1-day-period wavelet coherence (WC) curves extracted from Fig. 3 (wavelet correlation at 1-day period). We tested if WC curves from pairs of variables in the first column $\left(W C_{A}\right)$ shown higher correlation than WC curves from pairs of variables in the second column $\left(W C_{B}\right)$.

\begin{tabular}{lllcc}
\hline$W C_{\mathrm{A}}$ & WC & Time series & U statistic & p-value \\
\hline NDP SRr - NDP SFr & HO SRr - HO SFr & Spring-Summer & 1502 & $<0.0001$ \\
DFP SRr - DFP SFr & HO SRr - HO SFr & Spring-Summer & 1848 & $<0.00001$ \\
NDP SRr - NDP SFr & HO SRr - HO SFr & Summer-Autumn & 115.5 & 0.217 \\
DFP SRr - DFP SFr & HO SRr - HO SFr & Summer-Autumn & 104 & 0.400 \\
NDP SRr - NDP SFr & HO SRr - HO SFr & Autumn & 398.5 & 0.136 \\
DFP SRr - DFP SFr & HO SRr - HO SFr & Autumn & 392 & 0.164
\end{tabular}

Tab. 2 - Summary of the minimum adequate model of non-defoliated pine (NDP), defoliated pine (DFP), dead pine (DP) and Holm oak (HO) daily soil respiration. Soil water content (SWC), sap flow of non-defoliated pine (SF_NDP), defoliated pine (SF_DFP) and Holm oak (SF HO), as well as daily soil respiration were log transformed (see Materials and Methods for more details).

\begin{tabular}{|c|c|c|c|c|c|}
\hline Model & Variables & Estimate & SE & $t$-value & p-value \\
\hline NDP & Intercept & 1.624 & 2.467 & 0.658 & 0.512 \\
\hline \multirow[t]{5}{*}{$\left(R^{2}=0.23\right)$} & $T_{\mathrm{s}}$ & 0.410 & 0.095 & 4.328 & $<0.001$ \\
\hline & SWC & 4.291 & 2.130 & 2.014 & 0.046 \\
\hline & SF_NDP & 0.471 & 0.281 & 1.676 & 0.096 \\
\hline & $T_{\mathrm{s}} \cdot \mathrm{SF} \_N D P$ & 0.044 & 0.010 & 4.223 & $<0.001$ \\
\hline & $S W C \cdot S F \_N D P$ & 0.558 & 0.235 & 2.373 & 0.019 \\
\hline DFP & Intercept & -3.361 & 0.432 & -7.777 & $<0.001$ \\
\hline \multirow[t]{4}{*}{$\left(R^{2}=0.64\right)$} & SWC & -0.810 & 0.176 & -4.611 & $<0.001$ \\
\hline & $T_{\mathrm{s}}$ & 0.241 & 0.030 & 7.932 & $<0.001$ \\
\hline & SF_DFP & -0.153 & 0.047 & -3.265 & 0.001 \\
\hline & $T_{\mathrm{s}} \cdot \mathrm{SF} \_\mathrm{DFP}$ & 0.021 & 0.003 & 6.684 & $<0.001$ \\
\hline DP & Intercept & 1.289 & 0.284 & 4.540 & $<0.001$ \\
\hline \multirow[t]{2}{*}{$\left(R^{2}=0.76\right)$} & $T_{\mathrm{s}}$ & 0.072 & 0.005 & 14.606 & $<0.001$ \\
\hline & SF_HO & 0.171 & 0.026 & 6.617 & $<0.001$ \\
\hline $\mathrm{HO}$ & Intercept & -7.765 & 1.404 & -5.532 & $<0.001$ \\
\hline \multirow[t]{5}{*}{$\left(R^{2}=0.76\right)$} & $T_{\mathrm{s}}$ & 0.231 & 0.050 & 4.650 & $<0.001$ \\
\hline & SWC & -2.742 & 1.204 & -2.278 & 0.024 \\
\hline & $\mathrm{SF}$ HO & -0.477 & 0.154 & -3.104 & $<0.001$ \\
\hline & $T_{\mathrm{s}} \cdot \mathrm{SF} \_\mathrm{HO}$ & 0.021 & 0.005 & 4.090 & $<0.001$ \\
\hline & $\mathrm{SWC} \cdot \mathrm{SF} \_\mathrm{HO}$ & -0.181 & 0.128 & -1.415 & $<0.001$ \\
\hline
\end{tabular}


$23 \%$ of the seasonal variability. Hence, the effect of SF on SR had a synergistic effect with $T_{s}$ and SWC. In the case of DFP, the best model for SR included SWC and the interaction between $T_{\mathrm{s}}$ and $\mathrm{SF}$ as predictor variables and explained $64 \%$ of the seasonal variability. This interaction reflected that the higher the temperature, the larger the positive effect of SF on SR. The best model for SR in DP included the positive effect of $T_{s}$ and SF of HO (but not SF of NDP) as predictor variables and explained $76 \%$ of the seasonal variability.

Seasonal variability of HO SR was well explained $\left(R^{2}=0.76\right)$ by the interactions between $T_{s}$ and HO SF (positive effect) and between SWC and HO SF (negative effect) and explained $76 \%$ of the seasonal variability.

\section{Discussion}

\section{The influence of sap flow on soil} respiration

Aboveground plant activity influenced SR from hourly to seasonal timescales. At diel timescale, this effect was observed despite the photosynthesis-SR relationship could be partially masked by some fractions of SR non-directly dependent from photosynthesis, such as microbial decomposition of SOM and dead tissues (Kuzyakov 2006). It is important to emphasize that the observed SF influence on SR occurred regardless of changes in $T_{s}$ and gas diffusivity, which have been detected as confounding factors in previous studies (Janssens et al. 2001, Curiel Yuste et al. 2004, Vargas et al. 2011). Moreover, temperature corrections applied to SR and SF were highly restrictive (all potential effects of temperature were removed), so that we could even underestimate the real contribution of photosynthesis on SR.

The strong correlation of SF and SR at the diel time-scale was, however, not constant throughout time, being stronger at high SR and SF rates. Vargas et al. (2010) also found in a similar study system (mixed Mediterranean forest with Quercus and coniferous species) that the relationship between photosynthesis and SR at the diel scale was stronger during spring and after the first autumn rains, when both SR and photosynthesis are at their peak and not limited by water availability. Different studies suggest that, in semi-arid ecosystems, rain events after drought periods enhance soil heterotrophic respiration and thus total SR (Misson et al. 2006, Inglima et al. 2009). This main contribution from the heterotrophic component of SR has been supported by an increase in SR but not of root production (Misson et al. 2006) or an increase in SR despite vegetation senescence (Inglima et al. 2009). However, in our study we also observed an increase in SF after rain events at the beginning of fall, suggesting the restart of aboveground plant activity. Moreover, in our study site, periods with the strongest diel correlation between plant photosynthesis and SR did not necessarily coincide with periods of high autotrophic contribution to total SR. Indeed, the autotrophic SR contribution to total SR could be higher during mid-summer and autumn, as observed in a parallel work carried out in the same study system (Barba et al. 2016a), coinciding with the periods of lowest daily SF-SR correlations found in this study. This could indicate that during unfavourable periods (less $\mathrm{C}$ fixation and less soil activity due to higher water stress), the autotrophic contribution to SR could be decoupled from concurrent plant photosynthetic activity, likely suggesting that under these circumstances SR would depend largely on the mobilization of existing $C$ reserves.

Wavelet coherence analysis showed very little lag between SR and SF at diel time scale in this drought-limited ecosystem, which means that changes in SF were followed very quickly by changes in SR. Since the direct phloem $\mathrm{C}$ transport rate in trees usually ranges between 0.5 to $1.0 \mathrm{~m} \mathrm{~h}^{-1}$ (Kuzyakov \& Gavrichkova 2010), the observed almost-simultaneous photosynthetic influence on SR, independent from tree height, was more likely related to the fast propagation of turgor waves and osmotic pressure in the phloem produced by the addition of recently assimilated carbohydrates into the phloem (as suggested by Mencuccini \& Holtta 2010) rather than to C translocation by mass flow. Other studies of time series analysis using VPD, PAR or GPP as proxies of photosynthesis have, however, reported lags of a few hours in the relationship between photosynthesis and SR (Tang et al. 2005, Misson et al. 2010, Vargas et al. 2011). The near absence of a SR-SF lag in our study could be partially explained by an existing delay between these commonly used proxies and tree-based SF at diel scale. Lags between evaporative demand, stomatal conductance and assimilation or between canopy photosynthetic rates and SF measured at breast height in the trunk (Ford et al. 2004) could account for the differences in lags between this study and others. Indeed, at the study site, lags up to $45 \mathrm{~min}$ were found between solar radiation and SF at breast height in the trunk during spring (R. Poyatos, unpublished data).

Photosynthetic activity not only determined SR at diel- but also at seasonal-time scale. Using daily averaged data we also observed that SF strongly influenced SR, although a large fraction of the variability remained unexplained. Comparatively, Irvine et al. (2008) reported that 10-day averages of sap flow alone explained $90 \%$ of the variability in SR at the same temporal scale in a Pinus ponderosa stand, but that site was not as severely affected by drought as our study site. In our case, SF also interacted with temperature and moisture to determine SR rates, in line with previous studies where both total SR and its autotrophic component were partially explained by temperature-moisture interaction at seasonal scale (Barba et al. 2016a). Other stud- ies also showed a strong impact on SR of the interaction between photosynthesis and other environmental drivers (Janssens et al. 2001, Reichstein et al. 2003). More specifically, drought conditions diminish both assimilation rates and photosynthates transport (Ruehr et al. 2009), leading to the uncoupling between canopy photosynthesis and belowground activity.

\section{Soil respiration and sap flow \\ relationship across the die-off and species replacement process}

We studied how SF affected SR in four trees (non-defoliated pine, defoliated pine, dead pine and Holm oak), representing four different stages of drought-induced die-off in Scots pine and its replacement by Holm oak. The lack of replicated measurements across tree types due to limited available solid-state $\mathrm{CO}_{2}$ sensors and limitations in power supply precluded statistical inference; hence, our results should be interpreted with caution. However, several previous studies at the same study site using different techniques showed differences between these different stages in SR (total or by components - Barba et al. 2013, 2016a, Pereira-Blanco 2014), in SF (Poyatos et al. 2013) and in photosynthesis rates (Salmon et al. 2015). Additionally, information of these previous studies were used for selecting representative trees from each stage, allowing the discussion of differences on the SR-SF relationship between trees, but also assuming that it would be somewhat speculative.

The photosynthesis influence on SR at diel and seasonal scales differed along the trees representing the drought-induced die-off and species-replacement gradient. At diel scale, SF influence was higher for SR beneath living Scots pine (both NDP and DFP) than beneath Holm oak (Tab. 1). This would suggest a more prominent role of pressure concentration waves as a fast signal transmission system (Thompson \& Holbrook 2003) in driving the relationship between SF and SR in living pines, but SR under oaks would tend to be more controlled by the mobilization of stored carbon. Mencuccini \& Holtta (2010) suggested that when the stored carbon is mobilized, the osmotic potential in phloem decreases, thereby reducing the signal transmission.

At seasonal scale, SF also influenced SR for all tree types of the gradient. However, environmental drivers and SF explained much more seasonal variability of SR under DFP than under NDP (64 and $23 \%$, respectively). The fact that non-defoliated pines tend to have higher carbohydrate reserves than defoliated pines (Poyatos et al. 2013, Salmon et al. 2015) may decouple the temporal variation of SR from that of SF. In contrast with results obtained at the diel time scale, SF exerted a stronger effect on $\mathrm{SR}$ at seasonal scale beneath $\mathrm{HO}$ than beneath living Scots pines. This suggests that mass flow of photoassimilates (slow transport mechanism) may be a more relevant 
control on SR beneath $\mathrm{HO}$ than beneath living pines, which was consistent with the daily scale findings.

An interesting result of both daily and seasonal analyses was that SR beneath DP seemed to be strongly determined by SF from close Holm oaks instead of SF from living pines. Wavelet analysis showed similar SR-SF daily patterns in DP and $\mathrm{HO}$, and seasonal variation in SR of DP was statistically explained by SF of HO. These results suggest that holm oaks, but not the surviving pines, may be colonizing the soil gaps left by dead pines. Indirect evidences of this $\mathrm{HO}$ colonization have also been reported for this study site, including convergence in soil bacterial diversity and community structure between DP and $\mathrm{HO}(\mathrm{Cu}$ riel Yuste et al. 2012) or similar fine roots respiration between living roots sampled beneath HO and DP (Pereira-Blanco 2014). This rhizosphere colonization of gaps created by the death of pines could be responsible for the soil respiration resilience observed in the study site (Barba et al. 2016a).

\section{Concluding remarks}

Our results show that time series analysis (specifically wavelet coherence analysis) is a powerful approach for studying the soil respiration dependency on aboveground plant activity. This approach could be simultaneously applied with other techniques such as labelling experiments with real-time isotopic analysis to better understanding of plant and soil interactions. Overall, our results show that aboveground tree activity affects soil respiration at different temporal scales in a droughtaffected forest. The association between sap flow and soil respiration varied seasonally and was clearly weakened during summer drought. Our results also reveal differences in the link between canopy photosynthesis and soil respiration, possibly associated with species-specific physiological differences between Scots pine and holm oak. Further studies should explore the link between sap flow and the autotrophic and heterotrophic components of soil respiration, in order to increase our understanding of how changes in aboveground activity influence belowground processes in water-limited forests.

\section{Acknowledgements}

The authors thank D. Riveros-Iregui for providing technical details for the set-up of the $\mathrm{CO}_{2}$ sensors and $\mathrm{M}$. Mencuccini and $\mathrm{R}$. Vargas for their valuable comments. This study was supported by the Spanish Government projects SECASOL (CGL2009-081 01), DRIM (CGL2010-16373), VULGLO (CGL 2010-22180-C03-03), SECADIN (CGL201232965), BIOCLIM (CGL2015-67419-R), SAPFLUXNET (CGL2014-5583-JIN) and VERONICA (CGL2013-42271-P), by the Government of Catalonia grants (2009-SGR-00247 and 2014-SGR-453) and by a Community of Madrid grant REMEDINAL 2 (CM S2009/ AMB-1783). JB was supported by FPI (BES-
2010-036558) scholarship from the Spanish Ministry of Economy and Competitiveness and by an unemployment benefit from Spanish Ministry of Labour and Social Insurance.

\section{Author contributions}

$J B, J C Y$ and FLL conceived and designed the experiment; JB, JCY and RP performed the experiment; JB, JCY, RMH and RP analysed the data; JB wrote the paper and all authors edited the manuscript.

\section{References}

Anderegg WRL, Kane JM, Anderegg LDL (2013). Consequences of widespread tree mortality triggered by drought and temperature stress. Nature Climate Change 3: 30-36. - doi: 10.1038/ nclimate1635

Barba J, Curiel Yuste J, Martínez-Vilalta J, Lloret F (2013). Drought-induced tree species replacement is reflected in the spatial variability of soil respiration in a mixed Mediterranean forest. Forest Ecology and Management 306: 79-87. doi: 10.1016/j.foreco.2013.06.025

Barba J, Curiel Yuste J, Poyatos R, Janssens IA, Lloret $F$ (2016a). Strong resilience of soil respiration components to drought-induced die-off resulting in forest secondary succession. Oecologia 182: 27-41. - doi: 10.1007/s00442-016-3567-

Barba J, Lloret F, Curiel Yuste J (2016b). Effects of drought-induced forest die-off on litter decomposition. Plant and Soil 402: 91-101. - doi: 10.1007/s11104-015-2762-4

Barba J, Cueva A, Bahn M, Barron-Gafford GA, Bond-Lamberty B, Hanson PJ, Jaimes A, Kulmala L, Pumpanen J, Scott RL, Wohlfahrt G, Vargas R (2017). Comparing ecosystem and soil respiration: review and key challenges of tower-based and soil measurements. Agricultural and Forest Meteorology 249: 434-443. - doi: 10.1016/j.agrformet.2017.10.028

Barton CVM, Ellsworth DS, Medlyn BE, Duursma RA, Tissue DT, Adams MA, Eamus D, Conroy JP, Mcmurtrie RE, Parsby J, Linder S (2010). Wholetree chambers for elevated atmospheric $\mathrm{CO}_{2}$ experimentation and tree scale flux measurements in south-eastern Australia: the Hawkesbury Forest Experiment. Agricultural and Forest Meteorology 150: 941-951. - doi: 10.1016/j.agr formet.2010.03.001

Bigler C, Bräker OU, Bugmann H, Dobbertin M, Rigling A (2006). Drought as an inciting mortality factor in scots pine stands of the Valais, Switzerland. Ecosystems 9: 330-343. - doi: 10.1007/s10021-005-0126-2

Binkley D, Giardina C (1998). Why do tree species affect soils? The warp and woof of tree-soil interactions. Biogeochemistry 42: 89-106. - doi: 10.1023/A:1005948126251

Carnicer J, Coll M, Ninyerola M, Pons X, Sánchez G, Peñuelas J (2011). Widespread crown condition decline, food web disruption, and amplified tree mortality with increased climate change-type drought. Proceedings of the $\mathrm{Na}$ tional Academy of Sciences USA 108: 1474-1478. - doi: 10.1073/pnas.1010070108

Curiel Yuste J, Janssens IA, Carrara A, Ceulemans R (2004). Annual Q(10) of soil respiration reflects plant phenological patterns as well as temperature sensitivity. Global Change Biology 10: 161-169. - doi: 10.1111/j.1529-8817.2003.0072 $7 . \mathrm{x}$

Curiel Yuste J, Barba J, Fernández-Gonzalez JA, Fernández-López $\mathrm{M}$, Mattana S, Nolis $\mathrm{P}$, Lloret $F$ (2012). Changes in soil bacterial community triggered by drought-induced gap succession preceded changes in soil $\mathrm{C}$ stocks and quality. Ecology and Evolution 2: 3016-3031. - doi: 10.1002/ece3.409

Ekblad A, Boström B, Holm A, Comstedt D (2005). Forest soil respiration rate and delta13C is regulated by recent above ground weather conditions. Oecologia 143: 136-142. - doi: 10.1007 |s00442-004-1776-z

Ford CR, Goranson CE, Mitchell RJ, Will RE, Teskey RO (2004). Diurnal and seasonal variability in the radial distribution of sap flow: predicting total stem flow in Pinus taeda trees. Tree physiology 24: 941-950. - doi: 10.1093/treephys/24.9. 941

Galiano L, Martínez-Vilalta J, Lloret F (2010). Drought-induced multifactor decline of scots pine in the pyrenees and potential vegetation change by the expansion of co-occurring oak species. Ecosystems 13: 978-991. - doi: 10.1007/ S10021-010-9368-8

Gaumont-Guay D, Black TA, Barr AG, Jassal RS, Nesic Z (2008). Biophysical controls on rhizospheric and heterotrophic components of soil respiration in a boreal black spruce stand. Tree physiology 28: 161-171. - doi: 10.1093/treephys/ 28.2.161

Granier A (1985). Une nouvelle methode pour la measure du flux de seve brute dans le tronc des arbres [A new method for measuring sap flow in tree trunks]. Annales des Sciences Forestieres 42 (2): 193-200. - doi: 10.1051/forest: 19850204

Grinsted A, Moore JC, Jevrejeva S (2004). Application of the cross wavelet transform and wavelet coherence to geophysical time series. Nonlinear Processes in Geophysics 11: 561-566. doi: 10.5194/npg-11-561-2004

Heres AM, Martínez-Vilalta J, Claramunt López B (2012). Growth patterns in relation to droughtinduced mortality at two Scots pine (Pinus sylvestris L.) sites in NE Iberian Peninsula. Trees 26: 621-630. - doi: 10.1007/so0468-011-0628-9 Högberg P, Nordgren A, Buchmann N, Taylor AF, Ekblad A, Högberg MN, Nyberg G, OttossonLöfvenius M, Read DJ (2001). Large-scale forest girdling shows that current photosynthesis drives soil respiration. Nature 411: 789-792. doi: $10.1038 / 35081058$

Hu J, Moore DJP, Riveros-Iregui DA, Burns SP, Monson RK (2010). Modeling whole-tree carbon assimilation rate using observed transpiration rates and needle sugar carbon isotope ratios. New Phytologist 185: 1000-1015. - doi: 10.1111/j.1469-8137.2009.03154.x

Inglima I, Alberti G, Bertolini T, Vaccari FP, Gioli B, Miglietta F, Cotrufo MF, Peressotti A (2009). Precipitation pulses enhance respiration of $\mathrm{Me}$ diterranean ecosystems: the balance between organic and inorganic components of increased soil $\mathrm{CO}_{2}$ efflux. Global Change Biology 15: 12891301. - doi: 10.1111/j.1365-2486.2008.01793.x Irvine J, Law BE, Martin JG, Vickers D (2008). Interannual variation in soil $\mathrm{CO}_{2}$ efflux and the response of root respiration to climate and $\mathrm{Ca}$ - 
nopy gas exchange in mature ponderosa pine. Global Change Biology 14: 2848-2859. - doi: 10.1111/j.1365-2486.2008.01682.x

Janssens IA, Lankreijer H, Matteucci G, Kowalski AS, Buchmann N, Epron D, Pilegaard K, Kutsch W, Longdoz B, Grunwald T, Montagnani L, Dore S, Rebmann C, Moors Grelle EJ A, Rannik U, Morgenstern K, Oltchev S, Clement R, Gudmundsson J, Minerbi S, Berbigier P, Ibrom A, Moncrieff J, Aubinet $M$, Bernhofer $C$, Jensen NO, Vesala T, Granier A, Schulze ED, Lindroth A, Dolman AJ, Jarvis PG, Ceulemans R, Valentini R (2001). Productivity overshadows temperature in determining soil and ecosystem respiration across European forests. Global Change Biology 7: 269-278. - doi: 10.1046/j.1365-2486.2001. 00412.x

Jones H (1992). Plants and microclimate: a quantitative approach to environmental plant physiology. Cambridge University Press, New York, pp. 1-427. - doi: 10.1017/CBO9780511845727

Kuzyakov $\mathrm{Y}$ (2006). Sources of $\mathrm{CO}_{2}$ efflux from soil and review of partitioning methods. Soil Biology and Biochemistry 38: 425-448. - doi: 10.1016/j.soilbio.2005.08.020

Kuzyakov Y, Gavrichkova O (2010). Time lag between photosynthesis and carbon dioxide efflux from soil: a review of mechanisms and controls. Global Change Biology 16: 3386-3406. - doi: 10.1111/j.1365-2486.2010.02179.x

Lloret F, Escudero A, Iriondo JM, Martínez-Vilalta $J$, Valladares $F$ (2012). Extreme climatic events and vegetation: the role of stabilizing processes. Global Change Biology 18: 797-805. doi: 10.1111/j.1365-2486.2011.02624.x

Maier M, Schack-Kirchner H (2014). Using the gradient method to determine soil gas flux: a review. Agricultural and Forest Meteorology, 192-193: 78-95. - doi: 10.1016/j.agrformet.2014. 03.006

Martínez-Vilalta J, Piñol J (2002). Drought-induced mortality and hydraulic architecture in pine populations of the NE Iberian Peninsula. Forest Ecology and Management 161: 247-256. doi: 10.1016/S0378-1127(01)00495-9

Martínez-Vilalta J, Lloret F (2016). Drought-induced vegetation shifts in terrestrial ecosystems: the key role of regeneration dynamics. Global and Planetary Change 144: 94-108. - doi: 10.1016/j.gloplacha.2016.07.009

Mencuccini M, Holtta T (2010). The significance of phloem transport for the speed with which canopy photosynthesis and belowground respiration are linked. New Phytologist 185: 189-203. - doi: 10.1111/j.1469-8137.2009.03050.x

Millington R, Quirk J (1961). Permeability of porous solids. Transactions of the Faraday Society 54: 1200-1207. - doi: 10.1039/tf9615701200

Misson L, Gershenson A, Tang J, McKay M, Cheng W, Goldstein A (2006). Influences of canopy photosynthesis and summer rain pulses on root dynamics and soil respiration in a young ponderosa pine forest. Tree physiology 26: 833-44. - doi: 10.1093/treephys/26.7.833

Misson L, Rocheteau A, Rambal S, Ourcival J-M,
Limousin J-M, Rodriguez R (2010). Functional changes in the control of carbon fluxes after 3 years of increased drought in a Mediterranean evergreen forest? Global Change Biology 16: 2461-2475. - doi: 10.1111/j.1365-2486.2009.02121.x Ninyerola M, Pons X, Roure JM (2007). Objective air temperature mapping for the Iberian Peninsula using spatial interpolation and GIS. International Journal of Climatology 27: 1231-1242. doi: $10.1002 /$ joc.1462

Pereira-Blanco E (2014). Response of fine root respiration to variations in biotic and abiotic factors in a mixed Mediterranean forest affected by drought induced secondary succession. Master thesis, Digital repository, Autonomous University of Barcelona, Bellaterra, Spain, pp. 1-27. [online] URL: http://ddd.uab.cat/re cord/133393? In=en

Poyatos R, Aguadé D, Galiano L, Mencuccini M, Martínez-Vilalta J (2013). Drought-induced defoliation and long periods of near-zero gas exchange play a key role in accentuating metabolic decline of Scots pine. The New Phytologist 200: 388-401. - doi: 10.1111/nph.12278

Reichstein M, Tenhunen JD, Roupsard O, Ourcival JM, Rambal S, Miglietta F, Peressotti A, Pecchiari M, Tirone G, Valentini $R$ (2002). Severe drought effects on ecosystem $\mathrm{CO}_{2}$ and $\mathrm{H}_{2} \mathrm{O}$ fluxes at three Mediterranean evergreen sites: revision of current hypotheses? Global Change Biology 8: 999-1017. - doi: 10.1046/j.1365-2486. 2002.00530.x

Reichstein M, Rey A, Freibauer A, Tenhunen J, Valentini R, Banza J, Casals P, Cheng YF, Grunzweig JM, Irvine J, Joffre R, Law BE, Loustau D, Miglietta F, Oechel W, Ourcival JM, Pereira JS, Peressotti A, Ponti F, Qi Y, Rambal S, Rayment M, Romanya J, Rossi F, Tedeschi V (2003). Modeling temporal and large-scale spatial variability of soil respiration from soil water availability, temperature and vegetation productivity indices. Global Biogeochemical Cycles 17: 11041115. - doi: 10.1029/2003GB002035

Riveros-Iregui DA, McGlynn BL, Epstein HE, Welsch DL (2008). Interpretation and evaluation of combined measurement techniques for soil $\mathrm{CO}_{2}$ efflux: discrete surface chambers and continuous soil $\mathrm{CO}_{2}$ concentration probes. Journal of Geophysical Research: Biogeosciences 113: 2156-2202. - doi: 10.1029/2008JG000811

Ruehr NK, Offermann CA, Gessler A, Winkler JB, Ferrio JP, Buchmann N, Barnard RL (2009). Drought effects on allocation of recent carbon: From beech leaves to soil $\mathrm{CO}_{2}$ efflux. New Phytologist 184: 950-961. - doi: 10.1111/j.1469-8137. 2009.03044.x

Salmon Y, Torres-Ruiz JM, Poyatos R, MartinezVilalta J, Meir P, Cochard H, Mencuccini M (2015). Balancing the risks of hydraulic failure and carbon starvation: a twig scale analysis in declining Scots pine. Plant, Cell and Environment 38: 2575-2588. - doi: 10.1111/pce.12572

Tang J, Baldocchi DD, Qi Y, Xu L (2003). Assessing soil $\mathrm{CO}_{2}$ efflux using continuous measurements of $\mathrm{CO}_{2}$ profiles in soils with small solid- state sensors. Agricultural and Forest Meteorology 118: 207-220. - doi: 10.1016/S0168-1923 (03)00112-6

Tang J, Baldocchi DD (2005). Spatial-temporal variation in soil respiration in an oak-grass savanna ecosystem in California and its partitioning into autotrophic and heterotrophic components. Biogeochemistry 73: 183-207. - doi: 10.10 07/s10533-004-5889-6

Tang J, Baldocchi DD, Xu L (2005). Tree photosynthesis modulates soil respiration on a diurnal time scale. Global Change Biology 11: 12981304. - doi: 10.1111/j.1365-2486.2005.00978.x

Thompson MV, Holbrook NM (2003). Scaling phloem transport: water potential equilibrium and osmoregulatory flow. Plant, Cell and Environment 26: 1561-1577. - doi: 10.1046/j.1365-30 40.2003.01080.x

Torrence C, Compo GP (1998). A practical guide to wavelet analysis. Bulletin of the American Meteorological Society 79: 61-78. - doi: 10.1175/ 1520-0477(1998)079<0061:APGTWA>2.0.CO;2

Vargas $R$, Detto $M$, Baldocchi DD, Allen MF (2010). Multiscale analysis of temporal variability of soil $\mathrm{CO}_{2}$ production as influenced by weather and vegetation. Global Change Biology 16: 1589-1605. - doi: 10.1111/j.1365-2486.20 09.02111.x

Vargas R, Baldocchi D, Bahn M, Hanson PJ, Hosman KP, Kulmala L, Pumpanen J, Yang B (2011). On the multi-temporal correlation between photosynthesis and soil $\mathrm{CO}(2)$ efflux: reconciling lags and observations. New Phytologist 191: 1006-1017. - doi: 10.1111/j.1469-8137.2011.03771.x Vayreda J, Martínez-Vilalta J, Gracia M, Retana J (2011). Recent climate changes interact with stand structure and management to determine changes in tree carbon stocks in Spanish forests. Global Change Biology 18: 1028-1041. - doi: 10.1111/j.1365-2486.2011.02606.x

Vilà-Cabrera A, Martínez-Vilalta J, Galiano L, Retana J (2013). Patterns of forest decline and regeneration across Scots pine populations. Ecosystems 16: 323-335. - doi: 10.1007/s10021-0129615-2

Yuan Z, Gazol A, Wang X, Xing D, Lin F, Bai X, Zhao Y, Li B, Hao Z (2012). What happens below the canopy? Direct and indirect influences of the dominant species on forest vertical layers. Oikos 121: 1145-1153. - doi: 10.1111/j.1600-0706.20 11.19757.x

\section{Supplementary Material}

Fig. S1 - Cross wavelet analyses output between (a) soil respiration (SR) and soil temperature (Temp), (b) SR and sap flow (SF), (c) SF and soil temperature, and (d) SR and soil water content (SWC) at non-defoliated pine from DOY 142 to 228 (May 22 2010 to August $16^{\text {th }} 2010$ ).

Link: Barba_2448@supploo1.pdf 